\title{
Neurotherapies and Alzheimer's: A Protocol-oriented Review
}

\author{
Javier Vigil ${ }^{1^{*}}$ and Lisa Tataryn ${ }^{2}$ \\ ${ }^{1}$ Licensed PGS, Madrid, Spain \\ ${ }^{2} \mathrm{MSc}, \mathrm{BCN}$, San Diego, California, USA
}

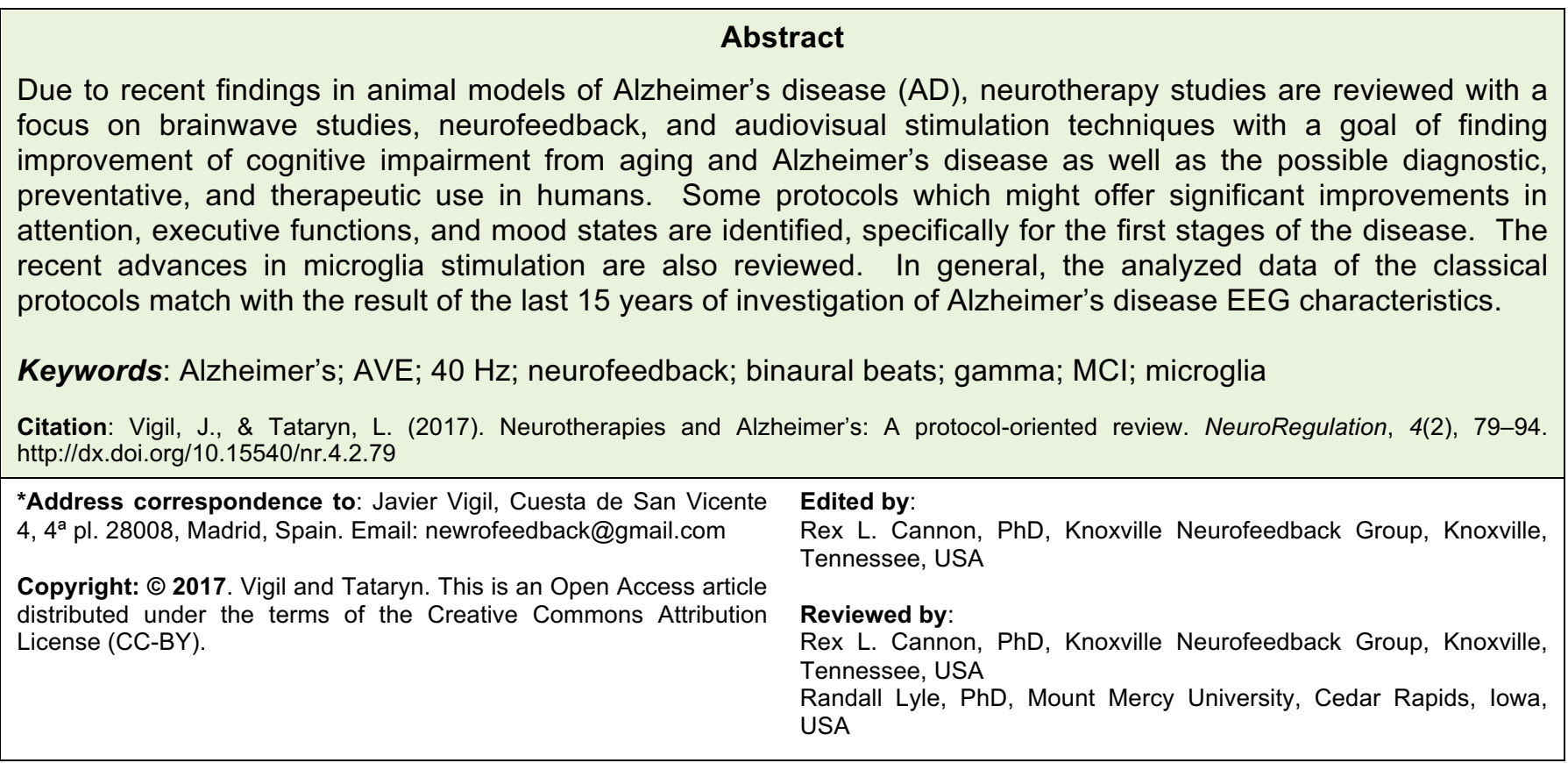

\section{Methods}

From January 1 to May 31, 2017, a search was conducted on PubMed and Scholar Google for papers or publications containing the terms Alzheimer, Alpha, Gamma, Neurofeedback, and Binaural beats.

\section{Alzheimer's Disease and Societal Burden}

Alzheimer's disease (AD) is one of the biggest social and health problems, with probably the largest economic cost due to the high incidence rate in aging societies. In a European country such as Spain, it is calculated that about 1 million people will be suffering from the disease by 2050 . As a neurodegenerative process, it slowly turns into a disease which impairs the person, causing loss of independence and, finally, death by immobility, drug complications, and/or cardiovascular problems (Prieto Jurczynska, Eimil Ortiz, López de Silanes de Miguel, \& Llanero Luque, 2011). The advancement of the disease causes problems such as memory loss, insomnia, and dementia. Rodrigues, Castro, and Spanish Red Cross (2014) find that personality changes in patients with $A D$, especially in neuroticism and openness. Some notable psychological findings are anosognosia and the lack of immediate memory. The latter is the consequence of the dysfunction of episodic memory (temporal left medial area), while anosognosia is in relation with hypoperfusion of the right dorsolateral prefrontal cortex (DLPFC) and inferior Mini-Mental State Examination (MMSE) scoring (Gil et al., 2001).

The psychological impact of the diagnosis on family members is also important; in fact, depression can have a significant impact on the family. Depression and anxiety are burdensome for the family and their environment. Notification of the diagnosis might cause a greater impact on the caregiver and the family than on the subject himself (Lladó, AntónAguirre, Villar, Rami, \& Molinuevo, 2008). The Handbook of Dementia (Lichtenberg, Murman, \& Mellow, 2003) says that AD causes two victims: the 
caregiver and the subject. Caregivers tend to be women (wife or daughter) suffering from anxiety, depression, and burnout; three studies on different continents sampled caregivers and reported respondents had similar burnout and mean ages: 52.5 in Japan, 55 in Spain, and 50 in Colombia (Gupta, Stankus, Fukuda, \& Okumura, 2015; Peinado Portero, 1998; Zambrano Cruz \& Ceballos Cardona, 2007).

One of the factors leading to caregiver burnout is the lack of handling and coping strategies. Caregiver burnout could improve with mindfulness-based programs, though the efficacy seems to be only short term (Franco, Sola, \& Justo, 2010). Effects in executive function (EF) are found; Stroop and anxiety and depression scores are impacted (Bromberg et al., 2015). Correa et al. (2015) find that cognitive impairments in caregivers are linked to decreased BDNF levels and increased cortisol/DHEA ratios.

\section{Pharmacological treatment}

Drug treatment has been based on cholinesterase inhibitors and the N-methyl-D-aspartate (NMDA) receptors such as memantine. Memantine seems to avoid the neurotoxic effect of the excessive level of glutamate present in AD. The goal of memantine is to avoid the development of the disease and increase the general cognitive capacity. However, the drug, as a single treatment or together with anticholinesterase, does not seem to work in the very first stages of the disease. Its efficacy on the last stage of impairment seems to also be limited (Schneider, Dagerman, Higgins, \& McShane, 2011). On top of this, extreme overdose could lead to a lack of consciousness (Kitagawa \& Sakurai, 2016). The meta-analysis of Matsunaga, Kishi, and Iwata (2015) finds that a memantine monotherapy produces a small improvement in cognition, behavior, and daily activities in studies with patients with an average age of 76 years old. Recently, some companies have had to abandon anti-amyloidal drugs due to failures in efficacy and issues with toxicity, such as in solanezumab and verubecestat trials (Hardy \& De Strooper, 2017), which is very bad news for the advancement of the pharmacological treatment of the disease.

\section{Cognitive rehabilitation}

Cognitive rehabilitation (e.g., brain training platforms, memory exercises, cognitive treatment, and psychomotor exercise via Kinect-based platforms) seems to be the option proposed from the field of Cognitive and Health Psychology in order to keep maximum self-autonomy for daily activities.
These treatments have been evaluated because they are the most common option of treatment in day centers and nursing homes, where it is very easy to keep optimum experimental follow-up. Gates and Sachdev (2014) found that cognitive training in preclinical people produces effects which can be transferred to other domains of daily activity. However, in meta-analysis Bahar-Fuchs, Hampstead, and Clare (2014) didn't find significant data that supports any option of cognitive training or rehabilitation. Clare and Woods (2004) analyzed several techniques of stimulation, rehabilitation, and training and did not find any significant effect.

The analysis of Frank and Konta (2005) is especially critical of the lack of outcome evaluation standards in this field, despite one third of the studies showing an improvement in the life of the subjects. Olazarán et al. (2010), on the other hand, analyze cognitive and educational treatments oriented to the life of the patient and the caregiver and find some evidence that nonpharmalogical therapies can improve the quality of life for both persons; for example, through a delay in the institutionalization of the patient by stressing training of daily life activities and behavior management. The FEEN study also shows that any strategy to delay the institutionalization of the patient is a positive benefit versus cost and merits attention and investment (Prieto Jurczynska et al., 2011, p. 29, 34). Recently, Orrell et al. (2017) found in an analysis that a structured and individualized stimulation therapy versus "treatment as usual" has no differential effect for people with dementia. Nonetheless, one of the conclusions is interesting: the caregivers believed that the experimental condition was "the best of things," such that the quality of the relationship between caregiver and the subject appeared enhanced after participation, but, on the other hand, the quality of life of the subject did not improve significantly.

\section{AD: Models of the Disconnection Syndrome}

The amyloidal hypothesis of $A D$ by Hardy and Selkoe (2002) keeps an increase in $\beta$-amyloidal "production versus clearance" as the main scientific explanation for the disease's cause. The beginning of the disease is hypothesized as an alteration of production of amyloid $\beta$-peptide $(A \beta)$, probably by genetic causes, which produces the accumulation of $A \beta$ and toxic plaque deposits. This mechanism could be initiated by a decrease in production of cholinergic inhibition.

The mechanism release damages in synapses, microglia activation, and astrocytes in M1 state and 
causes neuronal damage, oxidative load (NOx also helps $A \beta$ to accumulate in plaques), and inflammation. Later, tau neurofibrillary accumulation within neurons, apoptosis, and destruction of functional connective structures occurs. Microglia is "primed." The production of amyloidal plaques is believed to originate in the entorhinal medial temporal lobe (MTL) zone (Heneka et al., 2015), which is involved with episodic memory. Therefore, the most common concerns, which are a lack of recent memory in mild cognitive impairment $(\mathrm{MCl})$ and subjective memory complaints (SMC), could be a symptom of the advance of the disease in this area.

To this model, the addition of activity-dependent degeneration (ADD) connectivity and activity impairment (de Haan, Mott, van Straaten, Scheltens, \& Stam, 2012) is based on the extension of the disease via functional networks from the $\mathrm{MCl}$ status to the final phase. Parietal lobe and default mode network would suffer from the spread of the disease from subcortical areas, and then, finally, the frontal lobes would be affected. Loss of connectivity could mean an increment of activity due to the lack of inhibition, and the chronic neuronal damage would result in symptoms such as epilepsy.

Jack's (2013) model contributes that $A \beta$ is not enough for $A D$ to show, but we need to also have biomarkers of neurodegeneration such as cortical atrophy and hypometabolism. The model additionally suggests the possibility that $A \beta$ and tau are two distinct processes. The factors of cognitive reserve and brain resilience mediate the progression of the disease and the appearance of cognitive impairment (Jack, 2013, Point 4).

Hardy (2009) added vascular damage as a factor in relation to amyloidal accumulation that could explain cortical atrophy. The famous contribution of the Nun Study (Snowdon et al., 1997) highlights the preservation of the cardiovascular status as determinant to the appearance of the clinical symptoms. $A \beta$ is produced by the simple sensorimotor neuronal activity, as shown in APP transgenic mice (Bero et al., 2011). Choi et al. (2014) realized an experiment in petri dishes with 3D human cells in a familiar Alzheimer's model called "Alzheimer's in a dish," which seems to confirm that the model begins with amyloidal deposition, extends to tau fibers, and finally causes a generalized neuroinflammation.

\section{Brainwave studies in $\mathrm{MCl}$ and $\mathrm{AD}$}

Electroencephalography (EEG) analysis is a neuropsychological tool that allows measuring the brain activity through the analysis of the electrical activity registered with electrodes over the scalp. Improvement of systems, standardization of 10-20 placement system, and the existence of EEG databases allow us to register deviations (Collura, 2014, chapters 7-9; Kropotov, 2010). This enables us to elaborate on a hypothesis about the functionality of brain waves and centers according to psychological diseases and on protocols for the treatment of those.

The electrical activity is usually studied as delta $\delta$ $(0.5-4.0 \mathrm{~Hz})$, theta $\theta(4-8 \mathrm{~Hz})$, alpha $\alpha(8-12 \mathrm{~Hz})$, beta1 $\beta 1(13-20 \mathrm{~Hz})$, beta2 $\beta 2(20-30 \mathrm{~Hz})$, and gamma y $(30-100 \mathrm{~Hz})$. Gamma is a name that covers a broad or narrow range (Chapin \& RussellChapin, 2014). In y neurofeedback papers, y of 40 $\mathrm{Hz}$ is studied in the range of 36 to $44 \mathrm{~Hz}$ (Keizer, 2010). Tallon-Baudry and Bertrand (1999) consider that cognitive (poststimulus) operations fall in the range of 30 to $60 \mathrm{~Hz}$. We will later study $y$ and $A D$.

Moretti et al. (2004, 2012, 2015), in various articles, use specific ranges for study of $\mathrm{MCl}$ : $\delta(2.9-4.9), \theta$ (4.9-6.9), a1 (6.9-8.9), a2 (8.9-10.9), a3 (10.912.9), $\beta 1$ (12.9-19.2), $\beta 2$ (19.2-32.4), and y (32.4$45)$, which must be considered in future references for this author. Individual a frequency for subjects with $A D$, for example, fall to $8.7 \mathrm{~Hz}$ in MMSE 20.5, within $\alpha 1$ (Moretti et al., 2004). We will list the main findings according to the chronological order of appearance in $\mathrm{MCl}$ and $A D$, according to findings with EEG, magnetoencephalography (MEG), and quantitative electroencephalography (qEEG).

Theta increase: Kropotov (2010) explains the beginning of the disease as a lack of cholinergic inhibition of septum to the hippocampal circuits, which produces $\theta$ hyperactivity. This causes a tonic $\theta$ rhythm, which can be measured not only in temporal but frontal areas. Theta increased is confirmed by Moretti (Moretti, Prestia, Binetti, Zanetti, \& Frisoni, 2013) which finds a relation with hypoperfusion specifically in amnestic mild cognitive impairment $(\mathrm{aMCl})$. Theta increase is, however, not a specific sign of $A D$, since it also appears in normal aging groups (NAG), women, and vascular dementia subjects (Jeong, 2004).

Beta1 decrease and spreading: Dauwels, in his review, finds that the range $7-17 \mathrm{~Hz}$ is severely decreased in retrieval operative memory tasks in $A D$ (Dauwels, Vialatte, \& Cichocki, 2010). Poil et al. 
(2013) aim to show that there would be an abnormal distribution of the $\beta$-frequency range and $\beta$ peak in $A D$ (i.e., a faster, spread rhythm than no-AD).

Alpha decrease: $\alpha$ range is decreased in the range 8.0-10.5 Hz (Babiloni et al., 2009), specifically in central locations. Dauwels' review also confirms this reduction (Dauwels et al., 2010). Lack of $\alpha$ rhythm can be considered a lack of inhibition, cognitive flexibility, and behavior control (Sadaghiani \& Kleinschmidt, 2016). In a longitudinal study, Kuskowski, Mortimer, Morley, Malone, and Okaya (1993) found that inferior qEEG power values of 8$12 \mathrm{~Hz}$ were associated with later MMSE score decline.

Delta increase: an excessive $\delta$ increase in the range of 2-4 $\mathrm{Hz}$ can be considered a sign of neuroinflammation (Dauwels et al., 2010), which can in turn be a sign of disconnection and the final stages of the disease as well as lack of white matter in the frontal lobes. In addition, Babiloni et al. (2006) find increases of frontal $\delta$ in cases of aMCl. Dauwels suggests that EEG diagnosis could allow us to establish the real damage level in the brain of the subject, in order to adopt the most adequate treatment in terms of cost and opportunity.

\section{$\mathrm{MCl}$ diagnosis through EEG}

There are some articles which study the EEG and MEG profile of $\mathrm{MCl}$ vs. NAG as a control in order to ascertain which could suffer a $\mathrm{MCl}$ and possibly later lead to $A D$.

Rodriguez, Copello, Vitali, Perego, and Nobili (1999) stress the difficulty of distinguishing between NAG and those with real cognitive problems, even with people showing early signs of $A D$. Some NAG may have an $\alpha$ of slightly over $8 \mathrm{~Hz}$ without any major cognitive symptoms. The most important signs are the so-called "shift to the left" or generalized increase in slow frequencies, increase of $\theta$, global decrease of $8.0-9.5 \mathrm{~Hz} \alpha$ and $10.0-11.5 \mathrm{~Hz}$ ( $\alpha 1$ and $\alpha 2)$, and, lastly, an increase of $\delta$.

Kashefpoor, Rabbani, and Barekatain (2016) find the following possible $\mathrm{MCl}$ patterns in a group of patients who had cardiac catheterization with a MMSE of 27, determined through a fuzzy logic treatment of EEG: Increased ratio of slow and high frequencies ( $y$ excluded); relative power of the $\alpha$ band $(7.5-9.5 \mathrm{~Hz}), \beta 2(17.5-25 \mathrm{~Hz})$ reduced power (and posteriorized) and posterior increase of $\mathrm{y}$. The most interesting finding is that peak $\alpha$ seems to not be a marker (even though the contributions of anterior and posterior zones might be different).
Garcés et al. (2013) found an extended a peak of 7$11 \mathrm{~Hz}$ with MEG, which correlates to the lack of posterior rhythm and hippocampal reduction. For subjects with $\mathrm{MCl}$, these authors found an a peak of $9.05 \pm 0.90 \mathrm{~Hz}$. Van der Hiele et al. (2007) find that a reactivity (i.e., a EC vs. EO) is related to psychomotor and cognitive slowing and memory impairments.

Fauzan and Amran (2014) find a significant increase of Z-score of $\beta 2$ in F4 (a potential marker of anxiety/depression) in six elderly persons with $\mathrm{MCl}$ (MMSE < 23) vs. 14 controls. In EC, the increase of $\theta$ is found in F8, P4, and T6. F8 shows also a significant increase in $\delta$.

Finally, Babiloni et al. (2009), with Loreta, finds frontal increased $\delta$ (SMC and aMCl bigger than NAG), increased parieto-occipital amplitude in $\alpha 1$ and $\alpha 2$ (NAG and SMC bigger than $\mathrm{MCl}$ and aMCl) as two of the best EEG diagnostic markers (note the close MMSE scores: NAG 29, SMC 28.5, MCI 28 , aMCI 26.82).

\section{$\mathrm{MCl}$ converting to $\mathrm{AD}$}

We will now review which markers could indicate $\mathrm{MCl}$ converting to AD. The suggestion of some authors is to not use the diagnosis as an $A D$ diagnosis but rather to keep specific care actions, since EEG markers have been linked to damages in hippocampal areas, or frontal or parietal atrophy. As precise EEG markers, the ratio of $\alpha 3 / \alpha 2$ is linked to damage on the hippocampus $(0.75)$ and the $\theta / Y$ ratio with damage in the amygdala.

Moretti (2015) studies the power ratio of $\alpha 3 / \alpha 2$ as a diagnostic factor with SPECT neuroimaging help, showing cortical atrophy and temporo-parietal hypoperfusion. The $a$ band is determined from the individual $\alpha$ frequency, but the author gives a power ratio bigger than 1.17 of $\alpha 3(10.9-12.9 \mathrm{~Hz})$ vs. $\alpha 2$ $(8.9-10.9 \mathrm{~Hz})$ as a marker that links $\mathrm{MCl}$ conversion to $A D$ and bilateral hypoperfusion in precuneus. The main explanation by the author is that the lack of inhibitory interneurons provokes a hypersynchronization in the neuronal network precisely because of the atrophy process. Moretti et al. (2004) also found as a significant marker the bigger relative power in $\alpha 2$ in NAG (MMSE 29.09) vs. AD (MMSE 20.58).

Poil et al. (2013) studied the diagnostic power of several EEG markers in advanced AD. The most significant seems to be the $\beta(16-30 \mathrm{~Hz})$ peak, with a difference of $17.6 \mathrm{~Hz}$ in controls vs. $19.6 \mathrm{~Hz}$ in $\mathrm{MCl}$ converters, that results in a mean posterior decrease 
in MMSE from 28 to 24 . The width of $\beta$ peak seems to also be bigger in the AD group $(3 \mathrm{~Hz}$ vs. $<1.5 \mathrm{~Hz}$ in $\mathrm{MCl}$ ), and the a power ratio is also inferior $(<30 \%$ in $A D$ vs. $>30 \%$ in $\mathrm{MCl}$ ).

In the SMR/ $\beta 1$ range, sleep spindles, REM sleep time, and slow-wave production are shorter in $A D$ (Tsolaki, Kazis, Kompatsiaris, Kosmidou, \& Tsolaki, 2014). This could explain insomnia in $A D$ and altered sleep/vigilance patterns. In general, $\beta 1$ is one of the groups of frequencies with a larger decrease.

Hsiao, Wang, Yan, Chen, and Lin (2013) analyze a group of $\mathrm{MCl}$ with MMSE 22.7 vs. AD with 14.9, finding that the most important relation between MMSE and EEG scores can be found mostly in precuneus, posterior cingulate, and parietal and corresponds with increases in $\theta$ and decreases in $\alpha 1$ and $\alpha 2$. Rodriguez, Arnaldi, and Picco (2011) find a marker of $A D$ to be the lack of $\alpha$ blocking and its anteriorization.

From the psychological point of view, the increase of $\beta$ distribution suggests a neuronal background hyperexcitability, but an inefficient one. Sadaghiani and Kleinschmidt (2016) describe the need of a rhythms as "screen wipers" or slate cleaning, which allows the cyclic inhibition of signaling and control of information. Cognitive processes in $\alpha$ and $\beta$ seem to be damaged in the AD conversion process. With reference to $Y$ rhythm, the paradoxical increase in the rhythm could be on the local level, which means an adaptation to the disconnection and hypersynchronization syndrome. Van Deursen (2008) finds an increase in extended $y(30-100 \mathrm{~Hz})$ in $\mathrm{AD}$ and $\mathrm{MCl}$ vs. NAG.

In the very last stage of the disease, Rodriguez et al. (1999) find an increase in the $\theta$ relative power in the right zone linked with incontinence. The authors also find an increase in relative $\delta$ power in the right zone, which correlates with the incapacity for activities of daily life, leading to the possibility of death.

Dynamic analysis

The reduced complexity term in other bands is identified in the review by Dauwels et al. (2010) as a finding of EEG characteristics in AD.

Jeong (2004) explains two factors that have been found through nonlinear mathematical analysis on AD with the use of a single EEG channel. The $D_{2}$ component (number of independent variants necessary to explain the complexity of a system, also explained as the dimensional complexity of the system in a geographic space) is one of them. The occipital measure of this component is reduced in $A D$. The author suggests that one of the explanations is the lack of connectivity that leads to local disconnected networks. In control subjects, $D_{2}$ is increased in the eyes-open condition, as response to desynchronization of a rhythm. In $A D$ there is scarce difference between EO and EC (Pritchard, Duke, \& Coburn, 1991). This suggests a disconnection from external stimulus and damage to a rhythm-related circuits. The second component is $L_{1}$, a dynamic component linked with flexibility of processing (also explained as the possibility of growth from an initial condition), which could be decreased in AD. Jeong (2004) suggests that these components appear in the middle and last stages of $A D$ and show basic cognitive processes altered by the disease.

Lempel-Ziv (LZ) complexity has been used by Abásolo, Hornero, Gómez, García, and López (2006) and Gómez, Hornero, Abásolo, Fernández, and López (2006) in AD subjects vs. healthy agematched controls. LZ is a measure of distinct substrings happening in any sequence of data, which analyzes the rate of occurrence and change along the sequence (also explained as the capability of temporal change of a frequency according to the number of new patterns of it). Sequences of data obtained from an electrode (EEG) or an MEG point are extracted and turned into binary $(0,1)$ or 3 -item $(0,1,2)$ according to a threshold. An algorithm then calculates, left to right, when any given sequence is contained in the next sequence. Each new sequence makes a point, and the point is added to a counter $C(n)$, or $L Z$. For those interested in the meaning of a "sequence" (such as is considered by the LZ algorithm), it can typically contain from one to six data bits (measures). At a supposed screening rate of $170 \mathrm{~Hz}$ for 3400 data in a 20-s epoch, this means about $1 \mathrm{bit}=0.006 \mathrm{~s}$; therefore, sequences may last from 6 to $36 \mathrm{~ms}$.

As any putative measure, the worth of $L Z$ comes from the clinic and diagnostic power. $L Z$ is lower in $A D$. The receiver-operating characteristic $(R O C)$ for Abásolo et al. (EEG, AD MMSE 13.1/5.9) is 89.3, and for Gómez (MEG, AD MMSE 18/3.9) is 90.02 . Abásolo finds $90.9 \%$ specificity on P3, $90.9 \%$ sensitivity on $\mathrm{O} 1$, and differences in $\mathrm{P} 4$, and, interestingly, also in T5 (the area of object naming and recognition memory) in the most damaged $A D$ sample of both papers. 


\section{Neurotherapies}

Neurotherapies can be explained as therapies that use the brain rhythms and their modulation (Chapin \& Russell-Chapin, 2014, p. 3). This article will focus on neurofeedback (reinforcement) and audiovisual (stimulation). Other neurotherapies will also be mentioned.

Neurofeedback in NAG, SMC, MCI, and AD Neurodegenerative diseases may be remediated with the help of neurofeedback. The example is Parkinsonism, which has been treated with neurofeedback (Azarpaikan, Torbati, \& Sohrabi, 2014) showing success in balance improvement with reduction of $\theta$ in 01 .

The number of scientific articles dealing with neurofeedback in $\mathrm{MCl}$ or $\mathrm{AD}$ is limited (a fact already noted by Kropotov in 2010), which could suggest that the disease is incurable or untreatable. One of the biggest problems is the difficulty of the treatment in seniors. In an fMRI neurofeedback mood treatment in NAG, Rana et al. (2016) mention motivation and attention as the factors most affected by fatigue or lack of stimuli novelty, or because of the logistics of the sessions. We will mention firstly neurofeedback articles with NAG and SMC and secondly the ones with $\mathrm{MCl}$ or $\mathrm{AD}$ subjects.

In elderly normal people, there are some interesting articles. Becerra et al. (2012) uses a protocol of reduction of $\theta$ rhythm (in the $R O I$ where the ratio $\theta / \alpha$ is bigger). This results in an increase of the $\alpha$ rhythm in amplitude power, reduction of $\theta$ in midline and left frontal, and an increase in verbal capacity and memory. Also in normal seniors without $A D$ diagnosis, Angelakis et al. (2007) uses a protocol of elevation of peak $\alpha$ that increases processing speed and EF without significant improvement in memory.

Staufenbiel, Brouwer, Keizer, and van Wouwe (2014) use increases of $\beta 1$ and $y$ frequencies in location Fz. The results of the eight sessions show an increase within sessions, but without any other significant findings nor transference in the behavior. An explanation for this, proposed by the authors themselves, could be the scarce number of sessions (eight) and that the brain of the seniors could not recognize properly the reinforcement signal (a sound). Improvement in sleep and reduction of appetite (linked to increase in $\beta 1$ in F4) are noteworthy. Bird, Newton, Sheer, and Ford (1978) had already shown the feasibility of neurofeedback in the $\mathrm{Y}$ band (increase and decrease) in healthy people, from his first studies of $\alpha$ and $y$ range in cats.

We have to mention the classic protocol of "brain brightening," which basically is a reinforcement of the upper $\alpha$ range, a protocol similar to the work of Budzynski, Budzynski, and Tang (2007). Chapin and Russell-Chapin (2014, p. 187) find that this protocol is very possibly validated in children and adults. The work of Escolano, Navarro-Gil, GarciaCampayo, Congedo, and Minguez (2014), about the individual upper $\alpha$ in children with ADHD and adults, adds evidence to this protocol. In adults, Zoefel, Huster, and Herrmann (2011) find the improvement of cognitive functions with similar protocols in $\mathrm{Pz}$ and $\mathrm{Oz}$.

Now in subjects with $A D$, we have to mention the Luijmes, Pouwels, and Boonman (2016) paper. Using a qEEG and NeuroGuide database, the study uses a different protocol for each subject in 10 subjects on cholinesterase. The most common protocols are increases of median frequencies, $\alpha$ (spread in low and upper) in $\mathrm{Pz}$, and decreases of $\theta$ and $\beta 2$ in Fz. Using this procedure results in an increase of cognitive functions altered by $A D$. Lucas Koberda (2014) in his work with Loreta and Z-score mentions several cases of $A D$, but some of the specific cases $(7,9)$ do not show improvement with this technique.

In institutionalized resident subjects with mild $A D$ (MMSE 27) a multimodal brain fitness program, which included neurofeedback via qEEG (BrainMaster Technologies, Inc., Bedford, $\mathrm{OH}$ ) on a remarkable size $(N=127)$, showed a slight improvement in $84 \%$ of the subjects. A point of the treatment was psychological support (stimulation on sense of life). Reduction of excess $\beta 2$ was one of the goals of the treatment. The most significant outcome is the maintenance or increase of the hippocampus via fMRI check in a subsample of 17 , in $70 \%$ of the cases (note: physical exercise was fostered; Fotuhi et al., 2016).

Surmeli et al. (2016), with the help of qEEG neurofeedback, experience an important degree of success, due to the degree of impairment (MMSE 18.8) of the sample $(N=20)$ and the outcome after treatment (MMSE 24.5). A great number of subjects show brain atrophy and could leave medication after treatment and follow-up. Among the protocols used are suppression of slow waves and $\beta 2$, increase of $\beta 1$, and SMR increase in $\mathrm{Cz}-\mathrm{C} 4$. 
Table 1

Neurofeedback in Elderly: Protocols, ROI, and Results.

\begin{tabular}{|c|c|c|c|c|c|c|c|}
\hline $\begin{array}{l}\text { NAG } \\
\text { Studies }\end{array}$ & $\begin{array}{l}\text { Group } \\
(N)\end{array}$ & $\begin{array}{c}\text { Age } \\
(M / S D)\end{array}$ & MMSE & $\begin{array}{l}\text { Diagnostic? / } \\
\text { EEG System }\end{array}$ & Protocol / ROI & Test / Process & Outcome \\
\hline $\begin{array}{l}2007 \\
\text { Angelakis }\end{array}$ & NAG (3) & $\begin{array}{c}74 \\
(70-78)\end{array}$ & $\mathrm{N} / \mathrm{A}$ & $\mathrm{N} / \mathrm{A}$ & $\begin{array}{l}\alpha \text { IAF +2 Hz in POZ (3) } \\
\text { vs. } \alpha \text { amplitude } \\
\text { (Control, } 33 \times 24^{\prime} \text { ) }\end{array}$ & $\begin{array}{l}\text { Processing speed } \\
\text { and EF memory } \\
\text { improvement }\end{array}$ & Improves \\
\hline $\begin{array}{l}2011 \\
\text { Lecomte } \\
\text { Juhel }\end{array}$ & NAG (10) & $\begin{array}{c}75.25 \\
(65-85)\end{array}$ & $\mathrm{N} / \mathrm{A}$ & Only 4 sessions & $\begin{array}{l}\text { Inc. } \alpha, \text { Inc. } \alpha / \theta \\
\beta 1 / \theta \text { in the same session. } \\
C 3 / C 4\end{array}$ & Memory, stress & $\begin{array}{l}\text { Stress } \\
\text { improves }\end{array}$ \\
\hline $\begin{array}{l}2014 \\
\text { Staufenbiel }\end{array}$ & $\begin{array}{c}\text { NAG } \\
(10+10)\end{array}$ & 67.8 & $\mathrm{~N} / \mathrm{A}$ & $\mathrm{N} / \mathrm{A}$ & $\begin{array}{l}\text { Inc. } y \text { and } \beta 1 \text { in } F z \\
\left(8 \times 30^{\prime}\right)\end{array}$ & Operative memory & $\begin{array}{l}\text { WN, N/ } \\
\text { signific. }\end{array}$ \\
\hline $\begin{array}{l}2015 \\
\text { Gomez-Pilar* }\end{array}$ & NAG (11) & $\begin{array}{c}68 \\
(60-80)\end{array}$ & $\mathrm{N} / \mathrm{A}$ & $\begin{array}{l}\text { BCI Motor } \\
\text { Imagery }\end{array}$ & $\begin{array}{l}\text { Relative power in 12, 18, } 21 \\
\mathrm{~Hz} \\
\text { Zones C3, Cz, C4 }\end{array}$ & $\begin{array}{l}\text { Visospatial, verbal, } \\
\text { memory }\end{array}$ & Improves \\
\hline $\begin{array}{l}2009 \\
\text { Berman }\end{array}$ & $\begin{array}{c}A D \\
(16)\end{array}$ & $\mathrm{N} / \mathrm{S}$ & $\mathrm{N} / \mathrm{S}$ & qEEG & $\begin{array}{l}\text { Inc. } 10-18 \mathrm{~Hz} \\
35 \times 30 \text { ' average }\end{array}$ & $\begin{array}{l}\text { Verbal, orientation, } \\
\text { behavioral, EF }\end{array}$ & All but EF \\
\hline $\begin{array}{l}2011 \text { Collura } \\
\text { \$ \& Festa** }\end{array}$ & $\begin{array}{l}\text { AD + } \\
\text { NAG }\end{array}$ & $\begin{array}{c}74.8 \\
(62-86)\end{array}$ & AD 17 & qEEG & $\begin{array}{l}\text { Norm qEEG in } \mathrm{C} 3, \mathrm{C} 4, \mathrm{P} 3 \text {, } \\
\text { and } \mathrm{P} 4 \\
8 \text { sessions } \mathrm{x} \text { group }\end{array}$ & $\begin{array}{l}\text { Speed in spatial } \\
\text { orientation } \\
\text { Attention in spatial } \\
\text { orientation }\end{array}$ & $\begin{array}{l}\text { Yes, in } \\
\text { NAG } \\
\text { Yes, in AD }\end{array}$ \\
\hline $\begin{array}{l}2014 \\
\text { Koberda }\end{array}$ & $\begin{array}{l}\mathrm{AC}, \mathrm{MCl} \\
\mathrm{N} / \mathrm{D}\end{array}$ & $\mathrm{N} / \mathrm{A}$ & & $\begin{array}{l}\text { Loreta + } \\
\text { Z-score }\end{array}$ & Z-score & $\begin{array}{l}\text { Cognitive, mood, } \\
\text { other }\end{array}$ & $\begin{array}{l}\text { Improves } \\
71 \%\end{array}$ \\
\hline 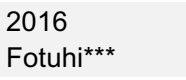 & $\begin{array}{l}\mathrm{MCl} \\
(127)\end{array}$ & $\begin{array}{c}70,7 \\
(10,5)\end{array}$ & 27 & $\begin{array}{c}\text { qEEG } \\
\text { BrainMaster }\end{array}$ & $\begin{array}{l}\text { Dec. } \theta \text { and } \delta \\
\text { Dec. } \beta 2\end{array}$ & $\begin{array}{l}\text { Cognitive, var. tests. } \\
\text { Hippocampal atrophy }\end{array}$ & $\begin{array}{l}\text { Improves } \\
\text { Reduction }\end{array}$ \\
\hline $\begin{array}{l}2016 \\
\text { Luijmes }\end{array}$ & $\begin{array}{l}A D \\
(10)\end{array}$ & $\begin{array}{c}71 \\
(64-78)\end{array}$ & & Yes & $\begin{array}{l}\text { Dec. } \theta(C z, F z), \text { Dec. } \beta 2 \text { (Fz) } \\
\text { SMR Inc. in Cz, Inc. } \alpha \text { Pz }\end{array}$ & $\begin{array}{l}\text { Memory, cognitive } \\
\text { tests }\end{array}$ & Improves \\
\hline
\end{tabular}

${ }^{*}=$ Personal communication: power ratio as neurofeedback objective (threshold) during brain-computer interface (BCl) imagery; ${ }^{* *}=$ Presentation by Festa, Heindel, Connors, Hirschberg, \& Ott (2009); ${ }^{* *}=$ Multimodal treatment included exercise, diet, and cognitive training; $\$=$ Financial interest disclosed. Main protocols mentioned for MCl by Budzynski et al., 2007, pp. 246-247: $\alpha$ increase, peak $\alpha$ increase in Pz, slow frequencies decrease $(2-8 \mathrm{~Hz})$. Acronyms: $\mathrm{POZ}=$ parieto occipital zone; $\mathrm{WM}=$ working memory; $\mathrm{VD}=$ vascular dementia

\section{Other Neurotherapies}

We have to mention other therapies, such as music therapy, with a possible effect on memory maintenance and as a pleasant daily activity (Lichtenberg et al., 2003, p. 39). A Canadian musical therapist specializing in $A D$ (ClementsCortes, Ahonen, Evans, Freedman, \& Bartel, 2016) has developed sing-along techniques (which stimulate memory and rhythm) and techniques of vibro-stimulation and stimulation with sounds at 40 $\mathrm{Hz}$. Also remarkable is the slight improvement of $A D$ with MMSE (0) in activity patterns and rest time in nursing homes with bright light therapies (Dowling, Graf, Hubbard, \& Luxenberg, 2007; Skjerve et al., 2004). Hansen (2014) reviews other neurotherapies such as TMS, TDCS, and TENS. Some of them show promising data in memory improvement and cognition, increasing plasticity and neuronal connectivity, modulating $\alpha$ and $\theta$ rhythms. There are no major studies on CES. 
The broad y range

As we have seen before, $y$ range usually is defined as activity from 30 to $100 \mathrm{~Hz}$. Gamma is defined as a mostly inhibiting activity, caused by interneurons on the body of pyramidal neurons. Gamma activity would be linked (phase and time) to other waves as $\alpha$ and $\theta$, and would be the result of an excitation and inhibition game, or the result of mutual inhibitions (Buzsáki \& Wang, 2012). Fast-spiking (FS), parvalbumin cells, a special interneuron type, seem to fire specifically at $25 \mathrm{~ms}$, creating a range of frequencies of 35 to $40 \mathrm{~Hz}$ (Cardin et al., 2009).

The appearance of this rhythm would not happen spontaneously but due to inner processes which would be induced by a stimulus or evoked (not directly). The difference between induction and evocation could be defined as $y$ directly evoked and depending, on phase and amplitude, on another rhythm or evoking stimulus. $40 \mathrm{~Hz}$, as an evoked rhythm, is temporarily linked to the appearance of a stimulus, meaning an "immediate" processing of the stimulus. Induced $\mathrm{y}$, on the contrary, has a bigger latency, is dependent from other cognitive processes (sensorial integration), and can be found on the wider $30-80 \mathrm{~Hz}$ range. The latter is subject to lateralization according to function: verbal stimulus induce $y$ on left hemisphere, image rotation induce right $\mathrm{y}$ activity (Tallon-Baudry, Bertrand, Wienbruch, Ross, \& Pantev, 1997).

Başar-Eroglu, Strüber, Schürmann, Stadler, and Başar (1996) call it a "Universal Operator," a kind of inner code that rules other brain oscillations. The authors summarize the range of $40-60 \mathrm{~Hz}$ with frontocentral attention processes, ambiguous image processing, and long-range brain synchronization. Ambiguous items would induce a bigger $y$ rhythm

We have seen the role of $y$ in cognitive processes. Now we will see its relationship with AD. Gamma is produced by FS interneurons. Through optogenetic stimulation, Cardin et al. (2009) provoke FS cells to produce a rhythm of $35-40 \mathrm{~Hz}$, which produces a suppression of sensorial stimuli. The inhibitor role of $\mathrm{Y}$ rhythm is demonstrated in a transgenic mouse model (hAPP) in which hypersynchronization is produced while $\mathrm{Y}$ rhythm is reduced, producing memory and learning deficits and epilepsy (Verret et al., 2012). This suggests that a reduction of $y 40-\mathrm{Hz}$ range rhythm might produce similar symptoms as $\mathrm{AD}$.

Audiovisual entrainment techniques

Audiovisual entrainment is a stimulation technique which uses acoustic and photic stimulus simultaneously. In the case of elderly people, the use of neurofeedback and audiovisual entrainment (AVE) was used by Budzynski (Grove, 2011), which can be reviewed in the book Introduction to Quantitative EEG and Neurofeedback (Collura \& Siever, 2009). There are some AVE manuscripts (Siever, 2007) on ADHD, anxiety, depression, and PTSD. Teplan, Krakovská, and Štolc (2006a, $2006 \mathrm{~b})$ found short- and long-term effects of this audiovisual stimulation (AVS, $25 \times 20$ ', mixed median frequencies) therapy, which can be considered of linear and nonlinear effect.

Next, we will review studies on sound beats and photic stimulation in $10 \mathrm{~Hz}, 40 \mathrm{~Hz}$, and other frequencies used in aging and cognitive function improvement in the elderly.

\section{Click and monaural stimulation}

Click stimulation has been realized with sounds of very short duration, which lack any psychological meaning (just "ticks"), used mostly in dichotic psychophysiologic studies. Some of these studies are monaural stimulus directed to an ear. Pastor, Artieda, Arbizu, Valencia, and Masdeu (2003) find that the stimulus at $40 \mathrm{~Hz}$ activates the pontocerebellum area, a zone implicated in timing and cortical inhibition. The maximum response is shown in F3 when the stimulus was presented in the right ear, and the maximum response amplitude was shown when the frequency was $37.75 \mathrm{~Hz}$.

Ross, Picton, Herdman, and Pantev (2004) found that the ASSR (continuous stimuli response) is bigger when the listening is more active, not passive, with clicks at $40 \mathrm{~Hz}$. An analysis by Chaieb, Wilpert, Reber, and Fell (2015) confirms the importance of binaural and monaural stimulation.

Monaural beats in $10 \mathrm{~Hz}$ and $40 \mathrm{~Hz}$ had an anxiety reduction effect (measured through STAl-test; Chaieb, Wilpert, Hoppe, Axmacher, \& Fell, 2017). Monaural beats are beats which contain the same frequency in each ear, in this case a $40-\mathrm{Hz}$ frequency.

\section{Binaural beats in 10 and $40 \mathrm{~Hz}$}

Binaural beats are a technique which presents two different frequencies to left and right ears ( $f L$ and $f R$ ) that are felt and perceived as a single frequency ( $F$ ) which corresponds to the subtraction of the frequencies, where $F=f L-f R$.

Binaural stimulation at $40 \mathrm{~Hz}$ created by $300 / 340 \mathrm{~Hz}$ provokes effects in the style of concentration, promoting a bigger attention to the task (Colzato, 
Barone, Sellaro, \& Hommel, 2017). It is noteworthy that the task used is a visual one. On the other hand, it was found that any binaural stimulation, even low frequencies, evoke a $40-\mathrm{Hz}$ response (Ross, Miyazaki, Thompson, Jamali, \& Fujioka, 2014). This is important to understand $y$ as a timing, selection, and control frequency; the author attributes the $40-\mathrm{Hz}$ MEG response to interneuronal activation.

Referring to binaural stimulation in elderly people, their hearing capacity loss might have an influence in the response, especially due to loss of response in higher frequencies of sound processing structures. Grose and Mamo (2012) use a low frequency of $390 / 430 \mathrm{~Hz}$ and a high one of $810 / 850$ $\mathrm{Hz}$, finding that this last high one produced a very low-frequency generation response in the elderly group. In the low range, $36 \%$ of the subjects did not generate a measurable binaural $\mathrm{y}$ response, but those who did had an amplitude similar to the young group. The critical binaural fusion frequency (Ross et al., 2014) is $60 \mathrm{~Hz}$, where you cannot tell a pure tone from a vibrating one.

\section{Photic stimulation at 10 and $40 \mathrm{~Hz}$}

The visual part of the AVE stimulation consists of photic stimulation, typically an LED fast-flicker stimulus corresponding to the frequency that is desired to be induced. The higher amplitude response zone is the occipital zone. Pastor et al. (2003) find that the photic stimulation on the $40-\mathrm{Hz}$ range produces a lesser response than $10(\alpha), 15$ $(\beta 1)$, or $35 \mathrm{~Hz}$. Within the y range, Herrmann (2001) finds an absolute peak of amplitude in the photic stimulation at $36 \mathrm{~Hz}$, while at $39 \mathrm{~Hz}$ a subharmonic effect at $13.5 \mathrm{~Hz}$ would be noted. Tallon-Baudry et al. find two possible structures resonating: one occipital in $36 \mathrm{~Hz}$, one central in $39 \mathrm{~Hz}$ (TallonBaudry et al., 1997, 1999).

A study on photic stimulation on elderly people on the $\alpha$ band $(9.5-11.0 \mathrm{~Hz})$ improved a memory task (Williams, Ramaswamy, \& Oulhaj, 2006). The best results were obtained with frequencies between 10.0 and $10.5 \mathrm{~Hz}$ in the 67- to 92-year-old group. This band corresponds to the a "sink" happening in $A D$, as we have seen before.

Kikuchi et al. (2002) on photic stimulation at 5, 10, and $15 \mathrm{~Hz}$, give two important outcomes: first, in NAG people, the effect of photic stimulation in principal and harmonics is important (there is a true stimulation) and, second, stimulation in relatively young $A D$ subjects (mean age 59.4, MMSE 15.7) already shows damage in the $10-\mathrm{Hz}$ and $20-\mathrm{Hz}$ reverberating circuits, specifically showing the fourth harmonic of $5 \mathrm{~Hz}(20 \mathrm{~Hz})$. This effect (loss of resonance at $10 \mathrm{~Hz}$ ) had also been noted by Politoff, Monson, Hass, and Stadler (1992), who attributed this to the $A D$ pathology in the rhythm-generating circuits.

As we have seen in the Grose and Mamo (2012) study, we might ask ourselves how aging influences the visual perception of continuous flickering stimuli, say, between a continuous light and a flickering one. The paradigm is called Critical Flicker Fusion (CFF). $A D$ and NAG people show a $4-\mathrm{Hz}$ difference in this threshold against young controls (Cronin-Golomb et al., 1991). In this study, it is detailed how cortical and associative deficits-and not neuroophthalmologic ones-would probably be the cause. Another study (Mewborn, Renzi, Hammond, \& Miller, 2015) also finds a $3-\mathrm{Hz}$ difference between young and old ones, in a higher education sample. The difference correlates with EF capacity. Herrmann (2001) finds the CFF point in about $30 \mathrm{~Hz}$ in a general sample where a flicker is perceived as a still light.

Regarding safety and risk of seizures, Gary Garcia (2008), it was considered that photic stimulation in the broad range of $40 \mathrm{~Hz}$ is safe enough for $\mathrm{BCl}$ applications.

AVS and AVE

We have previously mentioned the work of Budzynski et al. (2007), in which the protocol mentioned is a mixed-frequencies one (AVS), ranging from 9 to $22 \mathrm{~Hz}$. Note there is a negative interaction in particular subjects with health pathologies (see p. 246, 248 for details). For improvements, see Table 2. In children, using 15and $40-\mathrm{Hz}$ alternating frequencies, there is a study in ADHD with 35 sessions, with outcomes in WISC improvement and concentration capacity (Olmstead, 2005). Gaspar et al. (2014) studied the effect of 20 AVE sessions of 30' in an AD group with MMSE 1820 (MoCA adapted). In this level of impairment, Gaspar et al. find that brain brightening $(\alpha 12 \mathrm{~Hz})$ produces a $50 \%$ increase in the $\alpha$ EEG rhythm and a good adherence. However, there is no finding in cognitive functions. 


\section{Table 2}

Audiovisual Stimulation: Protocols, Frequencies, and Results.

\begin{tabular}{|c|c|c|c|c|c|c|c|}
\hline Author & $\begin{array}{l}\text { Exp. } \\
\text { Group } \\
(N)\end{array}$ & $\begin{array}{c}\text { Age } \\
(M / S D)\end{array}$ & MMSE & $\begin{array}{c}\text { Type of } \\
\text { Stimulation / } \\
\text { Session }\end{array}$ & $\begin{array}{l}\text { Protocol / Frequency / } \\
\text { AVS/AVE }\end{array}$ & Test / Task / Trait & Outcome \\
\hline $\begin{array}{l}2005 \\
\text { Olmstead \$ }\end{array}$ & $24+6$ & $\begin{array}{l}\text { ADHD } \\
\text { Young }\end{array}$ & $\mathrm{N} / \mathrm{A}$ & $\begin{array}{l}\text { AVS (Freq. } \\
15-40 \mathrm{~Hz})\end{array}$ & $\begin{array}{l}\text { Protocol from } 15 \text { to } 40 \mathrm{~Hz} \\
\text { \& vice versa }\end{array}$ & WISC, concentration & Improves \\
\hline $\begin{array}{l}2006 \\
\text { Williams }\end{array}$ & $\begin{array}{l}8 \text { NAG } \\
\text { vs. } \\
8 \text { Young }\end{array}$ & $67 / 92$ & 30 & Photic & $\begin{array}{l}10 \mathrm{~Hz}(9,5-11 \mathrm{~Hz}) \\
\text { Group } 10-10,5 \mathrm{~Hz} \uparrow\end{array}$ & Memory tasks & Improves \\
\hline $\begin{array}{l}2014 \\
\text { Gaspar }\end{array}$ & $\begin{array}{l}6 \text { vs. } 4 \\
\text { CTRL }\end{array}$ & $\begin{array}{l}A D \\
84\end{array}$ & $18 / 20$ & $\begin{array}{l}\text { AVE } 20 \\
\text { ss } \times 30\end{array}$ & $\begin{array}{l}\text { AVE } 12 \mathrm{~Hz}^{*} \text { vs. } \\
0.1-0.2 \mathrm{CTRL}\end{array}$ & $\begin{array}{l}\text { Cognitive function, } \\
\text { memory }\end{array}$ & $\mathrm{N} /$ signific. \\
\hline $\begin{array}{l}2015 \\
\text { Colzato }\end{array}$ & $\begin{array}{c}18 \mathrm{BB} / \\
18 \mathrm{CTRL}\end{array}$ & $18 / 28$ & $N / A$ & Binaural & $40 \mathrm{~Hz}(300-340 \mathrm{~Hz})$ & $\begin{array}{l}\text { Reaction time, } \\
\text { concentration on task }\end{array}$ & Improves \\
\hline $\begin{array}{l}2017 \\
\text { Chaieb }\end{array}$ & 25 & 24 & $N / A$ & Monoaural & $\begin{array}{l}10 \mathrm{~Hz}, 40 \mathrm{~Hz} \\
\text { (Variable freq. carrier) }\end{array}$ & $\begin{array}{l}\text { Anxiety decrease: } \\
\text { ES } 0.6110 \mathrm{~Hz} \text {, } \\
0.3940 \mathrm{~Hz}\end{array}$ & Improves \\
\hline
\end{tabular}

${ }^{*}=$ As from Abstract, $12 \mathrm{cps}$; \$ = Financial interest disclosed; \# = University of Washington study (Budzynski et al., 2007, pp. 252-256).

\section{Microglia}

Hortega, with the help of tincture method by silver carbonate, discovered the microglia cells. This fact surprised Cajal himself. In the first documents by Hortega, they are classified as "stick-looking cells" (Stabchenzell, a term coined by Nissi), which are supposed to mean microglia in chronified priming state by infections (Fariña González \& Escalona Zapata, 2005). The sequence is studied as stick cells, amoeboid, and granuloadipose cells.

To understand the activity of microglia in relation with $A D$, we will briefly summarize the microglia activity as M1 (activated state, interleukin, and cytokine aggressive production) and M2 (true phagocytosis state, anti-inflammatory, or alternative activation). Microglia, in contact with $A \beta$, produces aggressive neuroinflammatory cytokines. A similar role is the one of astrocytes (Heneka et al., 2015). There would be a "true" microglia state (M2), which can correctly clean the milieu, and an "incorrect" activation state (M1) in $A D$, which, in fact, contributes to the spread of the pathology. Citing Heneka et al. (2015) again, microglia would be a "legitimate therapeutic target" in AD.

Microglia and y frequency stimulation in mice Leinenga and Götz (2015) stimulate the brains of transgenic mice with $A D$ using an ultrasound cavitation technique with a $10-\mathrm{Hz}$ frequency. The result in memory tasks is a $75 \%$ improvement. There are two effects in this kind of invasive technique: one of them is the opening of the hematoencephalic barrier. The second one is the activation of microglia itself (p. 5) with a more open structure and twice the amount of phagocytosis than the control group. The big problem of this technique in humans would be the temperature increase due to the cavitation procedure. Sommer (2015), later commenting on the Leinenga experiment, proposed that such results (increase of phagocytosis by microglia) could be obtained by laser stimulation, due to the effect on ATP.

Recently, laccarino and the Tsai lab group (laccarino et al., 2016) applied an optogenetic $40 \mathrm{~Hz}$ on interneurons type PV-FS, and later, a photic, exterior $40 \mathrm{~Hz}$ on mice, which improved the memory tasks, as in the case of Leinenga. The $y$ stimulation during a week ( 1 hour per day) modifies microglia to an alternative state, capable to reduce the amyloidal accumulation in occipital region in a mouse 5XFAD model (Aron \& Yankner, 2016).

At the cell level, several wave longitudes are studied. Cheng, Kiernan, Eliceiri, Williams, and Watters (2016) add that the mere exposure to blue light to mice microglia $(450 \mathrm{~nm}$, commonly used in optogenetics) in several frequencies and powers produces a decrease of proinflammatory genetic activation in microglia exposed to LPS (activated). The pattern of stimulation used was a nonrhythmic and a classic $10-\mathrm{Hz}$ optogenetic one. Both caused a decrease of proinflammatory factors activity (through increasing CoX2, a proinflammatory one). 
Duggett and Chazot (2014) worked with in vitro transgenic mouse cells, exposing them to highly toxic doses of oligomeric and $\beta A$ fiber. The ones radiated at $1068 \mathrm{~nm}$ could survive a larger amount (24\% more). In another experiment, Grillo, Duggett, Ennaceur, and Chazot (2013) reduced the $\beta A$ level in a transgenic mouse with exposition to $1072 \mathrm{~nm}$.

\section{Discussion: Neurotherapies}

We have reviewed different techniques of neurotherapies applied with different success on aging people with $\mathrm{MCl}$ or $\mathrm{AD}$.

\section{Neurofeed back}

A remarkable aspect is that neurofeedback has not produced any lateralized protocol on $\mathrm{SMC} / \mathrm{MCl}$ with memory impairment, with evidence (Rusinek et al., 2004; Chan et al., 2001) of larger atrophy on the medial temporal lobe in the left temporal lobe which correlates with loss of episodic memory, atrophy, and MMSE rates. To check the importance of T3 and T5 (close to the hippocampus and amygdala), see Hammond (2005) for $\delta$ and $\theta$ findings in aging and dementia and suggested diagnostic montages.

Most of the protocols used in NAG or light MCI use $\alpha$ increase, $\theta$ decrease, or $\alpha / \theta$ protocols. One of the neurofeedback protocols used for improvement of cognitive functions in elderly has been the brain brightening, which can be considered as an established protocol (Chapin \& Russell-Chapin, 2014 , p. 187) for elderly with mild cognitive problems. Keeping a healthy a rhythm in aging people and with $\mathrm{MCl}$ can be considered a goal, given the relationship of impairment in the rhythm with cognitive and memory problems. An advantage is that this protocol can work with few sessions. Position in POZ seems to help memory (for evidence, see Table 1).

Beta increase protocols in the $\beta 1$, central positions, works in a $\mathrm{BCl}$ screen environment with cognitive, but not attention, improvement (Gomez-Pilar, Corralejo, Nicolas-Alonso, Álvarez, \& Hornero, 2016). Surmeli et al. (2016) use two ADHD classic protocols in $\mathrm{C} 3(\theta / \beta)$ and $\mathrm{C} 4(\mathrm{SMR})$. Gamma training seems to not have a significant outcome, and chances of activating frontal $\beta 2$ seem to be an important negative point in the aging population.

With reference to $A D$ patients, neurofeedback has shown that some patients still keep a fair neuroplasticity level. The outcomes are limited in memory issues, but interesting in orientation, EF, and verbal capacity. Most of the success cases in
$A D$ have used qEEG or Z-score-based neurofeedback and a standard number of sessions (20-30).

Protocols of frontal slow reduction, as suggested by Budzynski et al. (2007), do increase $\alpha$ amplitude and recover cognitive functions. Note that, in $A D$, only Luijmes et al. (2016) use a Pz a increase protocol.

Surmeli et al. (2016) uses two ADHD classic protocols in $C 3(\theta / \beta)$ and $C 4(S M R)$. Increase of $\beta 1$ in central positions and reduction of $\beta 2$ are also used.

Berman used a neurofeedback reinforcement protocol in the median range, finding as most significant that the capacity of existing memory in the subject is, in fact, an independent variable which correlates with the result of the treatment. This suggests that treatment must adapt to the cognitive status of the subject, as well as outcome expectative from the treatment (Berman \& Frederick, 2009).

\section{Bianaural, Photic, and AVE}

As we have seen, the different modalities of stimulation with clicks and waves in 10 and $40 \mathrm{~Hz}$ seem safe and in no case is there reference to problems of photosensitivity (epilepsy) caused by the stimulation. Anxiety is reduced in $40 \mathrm{~Hz}$ BB in audio stimulation alternatives (though a caveat of session duration should be set). It produces an improvement in attention, reaction time, and distraction-free style with a temporal effect.

Gaspar et al. (2014) AVE study in $12 \mathrm{~Hz}$, of brain brightening, on the upper $\alpha$ ( $\alpha 3$ as per Moretti) are disappointing as there is no cognitive, behavioral, nor attentional improvement in the MMSE 18/20 group. Williams's photic study, centered in $10 \mathrm{~Hz}$, however, produced improvement in memory. It seems, therefore, that stimulation techniques in $\mathrm{NAG}, \mathrm{MCl}$, and $\mathrm{AD}$ must be narrowly centered in 10 $\mathrm{Hz}$ and $40 \mathrm{~Hz}$. Protocols of AVS in median frequencies may help refresh cognitive function.

\section{Discussion: Microglia}

As the reader might have noted, there is not any explanation of a causal, direct relationship or link between any stimulation therapy and changes in microglia.

In $A D$, there seems to exist a basic problem which is that microglia do not function correctly. Cherry, Olschowka, and O'Banion (2014) propose that microglia is chronically activated in M1 and that this status is not the right one for $\beta A$ cleaning, having to 
change to $\mathrm{M} 2$ status $(\mathrm{M} 2 \mathrm{a}, \mathrm{M} 2 \mathrm{c})$ for alternative activation. The change is activated by TREM2, which increases phagocytosis of plaques and M2 number. TREM2 level increases in presymptomatic aMCl due to the growing accumulation of amyloid and tau, some years before (Suárez-Calvet et al., 2016).

Gamma photic entrainment, used in laccarino's manuscript (2016), could possibly have an action mechanism of: 1) microglia activation to a phagocytosis state, or mobilization to amyloid, 2) reduction in the amount of amyloid and/or tau (Aron \& Yankner, 2016), and/or 3) stimulation of interneurons and effect via neurotransmitters or in the milieu (intersynapsis).

In optogenetic mice studies, we have also seen that there would be a wave longitude effect (white, red, blue, and NIR Light) and possibly a frequency one. It would not work for the resonance effect on brain circuitry but for mere photic stimulation in different levels under the cellular one, be it genetic or metabolic.

\section{Conclusion: Neurotherapies in Aging and Alzheimer's}

EEG diagnosis to check the $\mathrm{MCl}$ status seems a valid method to obtain data on the subjects, in order to check the advance of $A D$, since the spread seem to be a silent one, producing probably compensatory hiding mechanisms, while keeping normal MMSE rates. The use of combined markers seems to be the most sensible, having in mind the correlation of some of them with atrophy or hypoperfusion in some brain areas and the appearance of $A D$ phenotypes.

Neurotherapies seem reliable and safe in the population range having in mind the impairment status. We hope from future investigations the clarification of protocols applicable to $\mathrm{MCl}$ status which can limit conversion to Alzheimer's disease and improve psychological well-being, daily functioning, and cognitive status. Studies should include $A D$ well-being aspects other than memory such as psychomotor functioning, verbal improvement, anxiety, and other aspects which are not currently considered and constitute part of quality of life.

AD AVE studies should be accompanied with biomarkers which could reflect the outcome impact in a follow-up period. Known effects of the $Y$ stimulation-such as psychological and behavior activation and concentration capacity-must be taken into account and evaluated. There also opens a panorama of investigation with the different effects of audio and photic stimulation in the frequencies of 36 to $40 \mathrm{~Hz}$ which we have mentioned.

The new fields of investigation of neurotherapies must be the face of the future, and we must take into account not only the Cajal cells but also the Hortega ones.

\section{References}

Abásolo, D., Hornero, R., Gómez, C., García, M., \& López, M. (2006). Analysis of EEG background activity in Alzheimer's disease patients with Lempel-Ziv complexity and central tendency measure. Medical Engineering \& Physics, 28(4), 315-322. http://dx.doi.org/10.1016/j.medengphy.2005.07.004

Angelakis, E., Stathopoulou, S., Frymiare, J. L., Green, D. L., Lubar, J. F., \& Kounios, J. (2007). EEG neurofeedback: A brief overview and an example of peak alpha frequency training for cognitive enhancement in the elderly. The Clinical Neuropsychologist, 21(1), 110-129. http://dx.doi.org/10.1080 /13854040600744839

Aron, L., \& Yankner, B. A. (2016). Neurodegenerative disorders: Neural synchronization in Alzheimer's disease. Nature, 540(7632), 207-208. http://dx.doi.org /10.1038/540207a

Azarpaikan, A., Torbati, H. T., \& Sohrabi, M. (2014). Neurofeedback and physical balance in Parkinson's patients. Gait \& Posture, 40(1), 177-181. http://dx.doi.org /10.1016/j.gaitpost.2014.03.179

Babiloni, C., Frisoni, G. B., Pievani, M., Vecchio, F., Lizio, R., Buttiglione, M., ... Rossini, P. M. (2009). Hippocampal volume and cortical sources of EEG alpha rhythms in mild cognitive impairment and Alzheimer disease. Neurolmage, 44(1), 123135. http://dx.doi.org /10.1016/j.neuroimage.2008.08.005

Babiloni, C., Frisoni, G., Steriade, M., Bresciani, L., Binetti, G., Del Percio, C., ... Rossini, P. M. (2006). Frontal white matter volume and delta EEG sources negatively correlate in awake subjects with mild cognitive impairment and Alzheimer's disease. Clinical Neurophysiology, 117(5), 1113-1129. http://dx.doi.org/10.1016/j.clinph.2006.01.020

Bahar-Fuchs, A., Hampstead, B. M., \& Clare, L. (2014). Cognitive Training for Older Adults with $\mathrm{MCl}$ and Mild Dementia: State of the Science, Central Challenges, and Possible Solutions. Alzheimer's \& Dementia, 10(4), 157. http://dx.doi.org/10.1016/j.jalz.2014.04.138

Başar-Eroglu, C., Strüber, D., Schürmann, M., Stadler, M., \& Başar, E. (1996). Gamma-band responses in the brain: A short review of psychophysiological correlates and functional significance. International Journal of Psychophysiology, 24(12), 101-112. https://doi.org/10.1016/S0167-8760(96)00051-7

Becerra, J., Fernández, T., Roca-Stappung, M., Díaz-Comas, L., Galán, L., Bosch, J., ... Harmony, T. (2012). Neurofeedback in healthy elderly human subjects with electroencephalographic risk for cognitive disorder. Journal of Alzheimer's Disease, 28(2), 357-367. http://dx.doi.org /10.3233/JAD-2011-111055

Berman, M. H., \& Frederick, J. A. (2009). Efficacy of neurofeedback for executive and memory function in dementia. Alzheimer's \& Dementia, 5(4), e8. http://dx.doi.org/10.1016/j.jalz.2009.07.046

Bero, A. W., Yan, P., Roh, J. H., Cirrito, J. R., Stewart, F. R., Raichle, M. E., ... Holtzman, D. M. (2011). Neuronal activity regulates the regional vulnerability to amyloid- $\beta$ deposition. Nature Neuroscience, 14(6), 750-756. http://dx.doi.org/10.1038/nn.2801 
Bird, B. L., Newton, F. A., Sheer, D. E., \& Ford, M. (1978). Biofeedback training of $40-\mathrm{Hz}$ EEG in humans. Biofeedback and Self-Regulation, 3(1), 1-11. http://dx.doi.org/10.1007 /BF00998559

Bromberg, E., Corrêa, M., Vedovelli, K., Giacobbo, B., Souza, C., Lima, D., ... Argimon, I. (2015). Emotional Burden Effects on Attention and Executive Function in Family Caregivers of Alzheimer Patients. Frontiers in Human Neuroscience, Conference Abstract: XII International Conference on Cognitive Neuroscience (ICON-XII). http://dx.doi.org/10.3389 /conf.fnhum.2015.217.00054

Budzynski, T., Budzynski, H. K., \& Tang, H.-Y. (2007). Brain brightening. In Handbook of neurofeedback: Dynamics and clinical applications (pp. 231-265). Boca Raton, FL: CRC Press. http://dx.doi.org/10.1201/b14658-15

Buzsáki, G., \& Wang, X.-J. (2012). Mechanisms of gamma oscillations. Annual review of neuroscience, 35, 203-225. http://doi.dx.org/10.1146/annurev-neuro-062111-150444 Retrieved from http://annualreviews.org/doi/abs/10.1146 lannurev-neuro-062111-150444

Cardin, J. A., Carlén, M., Meletis, K., Knoblich, U., Zhang, F., Deisseroth, K., ... Moore, C. I. (2009). Driving fast-spiking cells induces gamma rhythm and controls sensory responses. Nature, 459(7247), 663-667. http://dx.doi.org $/ 10.1038 /$ nature 08002

Chaieb, L., Wilpert, E. C., Hoppe, C., Axmacher, N., \& Fell, J. (2017). The Impact of Monaural Beat Stimulation on Anxiety and Cognition. Frontiers in Human Neuroscience, 11, 251. http://dx.doi.org/10.3389/fnhum.2017.00251

Chaieb, L., Wilpert, E. C., Reber, T. P., \& Fell, J. (2015). Auditory beat stimulation and its effects on cognition and mood states. Frontiers in Psychiatry, 6, 70. http://dx.doi.org/10.3389 /fpsyt.2015.00070

Chan, D., Fox, N. C., Scahill, R. I., Crum, W. R., Whitwell, J. L., Leschziner, G., ... Rossor, M. N. (2001). Patterns of temporal lobe atrophy in semantic dementia and Alzheimer's disease. Annals of Neurology, 49(4), 433-442. http://dx.doi.org/10.1002/ana.92

Chapin, T. J., \& Russell-Chapin, L. A. (2014). Neurotherapy and neurofeedback: Brain-based treatment for psychological and behavioral problems. New York, NY: Routledge.

Cheng, K. P., Kiernan, E. A., Eliceiri, K. W., Williams, J. C., \& Watters, J. J. (2016). Blue Light Modulates Murine Microglial Gene Expression in the Absence of Optogenetic Protein Expression. Scientific Reports, 6, 21172. http://dx.doi.org /10.1038/srep21172

Cherry, J. D., Olschowka, J. A., \& O'Banion, M. K. (2014). Neuroinflammation and M2 microglia: the good, the bad, and the inflamed. Journal of Neuroinflammation, 11, 98. http://doi.org/10.1186/1742-2094-11-98

Choi, S. H., Kim, Y. H., Hebisch, M., Sliwinski, C., Lee, S., D'Avanzo, C., ... Kim, D. Y. (2014). A three-dimensional human neural cell culture model of Alzheimer's disease. Nature, 515(7526), 274-278. http://dx.doi.org $/ 10.1038 /$ nature 13800

Clare, L., \& Woods, R. T. (2004). Cognitive training and cognitive rehabilitation for people with early-stage Alzheimer's disease: A review. Neuropsychological Rehabilitation,14(4), 385-401. http://dx.doi.org/10.1080/09602010443000074

Clements-Cortes, A., Ahonen, H., Evans, M., Freedman, M., \& Bartel, L. (2016). Short-term effects of rhythmic sensory stimulation in Alzheimer's disease: An exploratory pilot study. Journal of Alzheimer's Disease, 52(2), 651-660. http://dx.doi.org/10.3233/JAD-160081

Collura, T. F. (2014). Technical foundations of neurofeedback. New York, NY: Routledge.

Collura, T., \& Festa, E. (2011). Validation of a Global Live ZScore Protocol in a Randomized, Sham-Controlled Study of Cognitive Decline in Aging. Selected Abstracts of Conference Presentations at the 2011 International Society for
Neurofeedback and Research (ISNR) 19th ISNR Conference, Phoenix, Arizona, Journal of Neurotherapy, 15(4), 401-451. http://dx.doi.org/10.1080/10874208.2011.623098

Collura, T. F., \& Siever, D. (2009). Audio-visual entrainment in relation to mental health and EEG. In Introduction to Quantitative EEG and Neurofeedback (pp. 195-224). Burlington, MA: Elsevier. http://doi.org/10.1016/b978-0-12374534-7.00008-3

Colzato, L. S., Barone, H., Sellaro, R., \& Hommel, B. (2017). More attentional focusing through binaural beats: Evidence from the global-local task. Psychological Research, 81(1), 271-277. http://doi.org/10.1007/s00426-015-0727-0

Corrêa, M., Vedovelli, K., Giacobbo, B. L., de Souza, C. E., Ferrari, P., de Lima Argimon, I. I., ... Bromberg, E. (2015). Psychophysiological correlates of cognitive deficits in family caregivers of patients with Alzheimer Disease. Neuroscience, 286, 371-382. http://dx.doi.org/10.1016 /j.neuroscience.2014.11.052

Cronin-Golomb, A., Corkin, S., Rizzo, J. F., Cohen, J., Growdon, J. H., \& Banks, K. S. (1991). Visual dysfunction in Alzheimer's disease: Relation to normal aging. Annals of Neurology, 29(1), 41-52. http://dx.doi.org/10.1002 lana.410290110

Dauwels, J., Vialatte, F., \& Cichocki, A. (2010). Diagnosis of Alzheimer's disease from EEG signals: Where are we standing? Current Alzheimer Research, 7(6), 487505. http://dx.doi.org/10.2174/156720510792231720

de Haan, W., Mott, K., van Straaten, E. C. W., Scheltens, P., \& Stam, C. J. (2012). Activity Dependent Degeneration Explains Hub Vulnerability in Alzheimer's Disease. PLoS Computational Biology, 8(8), e1002582. http://dx.doi.org /10.1371/journal.pcbi.1002582

Dowling, G. A., Graf, C. L., Hubbard, E. M., \& Luxenberg, J. S. (2007). Light treatment for neuropsychiatric behaviors in Alzheimer's disease. Western Journal of Nursing Research, 29(8), 961-975. http://dx.doi.org/10.1177 10193945907303083

Duggett, N. A., \& Chazot, P. L. (2014). Low-Intensity Light Therapy $(1068 \mathrm{~nm})$ Protects CAD Neuroblastoma Cells from $\beta$-Amyloid-Mediated Cell Death. Biology and Medicine, 1, 103. http://dx.doi.org/10.4172/0974-8369.S1-003

Escolano, C., Navarro-Gil, M., Garcia-Campayo, J., Congedo, M., \& Minguez, J. (2014). The effects of individual upper alpha neurofeedback in ADHD: An open-label pilot study. Applied Psychophysiology and Biofeedback, 39(3-4), 193-202. http://dx.doi.org/10.1007/s10484-014-9257-6

Fariña González, J., \& Escalona Zapata, J. (2005). La obra de Pío del Río Hortega y sus consecuencias en la neuropatología. Arbor, 181(714), 221-232. http://dx.doi.org /10.3989/arbor.2005.i714.431

Fauzan, N., \& Amran, N. H. (2015). Brain dynamics of mild cognitive impairment $(\mathrm{MCl})$ from EEG features. Procedia Social and Behavioral Sciences, 165, 284-290. http://dx.doi.org/10.1016/j.sbspro.2014.12.633

Festa, E. K., Heindel, W. C., Connors, N. C., Hirschberg, L., \& Ott, B. R. (2009). Neurofeedback training enhances the efficiency of cortical processing in normal aging. Journal of Cognitive Neuroscience: Cognitive Neuroscience Society Annual Meeting Program, A11(Suppl.), 41.

Fotuhi, M., Lubinski, B., Hausterman, N., Riloff, T., Hadadi, M., Raji, C. A., \& Trullinger, M. (2016). A personalized 12-week "Brain Fitness Program" for improving cognitive function and increasing the volume of hippocampus in elderly with mild cognitive impairement. The Journal of Prevention of Alzheimer's Disease. http://dx.doi.org/10.14283/jpad.2016.92

Franco, C., Sola, M. d. M., \& Justo, E. (2010). Reducción del malestar psicológico y de la sobrecarga en familiares cuidadores de enfermos de Alzheimer mediante la aplicación de un programa de entrenamiento en Mindfulness [Reducing psychological discomfort and overload in Alzheimer's family 
caregivers through a mindfulness meditation program]. Revista Española de Geriatría y Gerontología, 45(5), 252-258. http://dx.doi.org /10.1016/j.regg.2010.03.006

Frank, W., \& Konta, B. (2005). Cognitive training for dementia. GMS Health Technology Assessment, 1, 10. Retrieved from http://europepmc.org/articles/PMC3011315

Garcés, P., Vicente, R., Wibral, M., Pineda-Pardo, J. A., López, M. E., Aurtenetxe, S., ... Fernández, A. (2013). Brain-wide slowing of spontaneous alpha rhythms in mild cognitive impairment. Frontiers in Aging Neuroscience, 5, 100. http://dx.doi.org/10.3389/fnagi.2013.00100

Garcia, G. (2008). High frequency SSVEPs for BCl applications. In Computer-Human Interaction. April, 2008. Retrieved from http://hmi.ewi.utwente.nl/chi2008/chi2008_files/garcia.pdf

Gaspar, P., Elliott, J., Algase, D., Gokula, M., Siddiqui, S. A., Vanguru, L., ... Li, X. (2014). Efficacy of Brain Brightening for Enhancing Performance and EEG Alpha Rhythm in Early and Middle Stage Dementia. Journal of Post-Acute and LongTerm Care Medicine, 15(3), B26B27. http://dx.doi.org/10.1016/j.jamda.2013.12.071

Gates, N. J., \& Sachdev, P. (2014). Is Cognitive Training an Effective Treatment for Preclinical and Early Alzheimer's Disease? Journal of Alzheimer's Disease, 42(Suppl. 4), S551-S559. http://dx.doi.org/10.3233/JAD-141302

Gil, R., Arroyo-Anllo, E. M., Ingrand, P., Gil, M., Neau, J. P., Ornon, C., \& Bonnaud, V. (2001). Self-consciousness and Alzheimer's disease. Acta Neurologica Scandinavica, 104(5), 296-300. http://doi.org/10.1034/j.1600-0404.2001.00280.x

Gómez, C., Hornero, R., Abásolo, D., Fernández, A., \& López, M. (2006). Complexity analysis of the magnetoencephalogram background activity in Alzheimer's disease patients. Medical Engineering \& Physics, 28(9), 851-859. http://dx.doi.org /10.1016/j.medengphy.2006.01.003

Gomez-Pilar, J., Corralejo, R., Nicolas-Alonso, L. F., Álvarez, D., \& Hornero, R. Medical \& Biological Engineering \& Computing, 54(11), 1655-1666. http://dx.doi.org/10.1007/s11517-016$1454-4$

Grillo, S. L., Duggett, N. A., Ennaceur, A., \& Chazot, P. L. (2013). Non-invasive infra-red therapy $(1072 \mathrm{~nm})$ reduces $\beta$-amyloid protein levels in the brain of an Alzheimer's disease mouse model, TASTPM. Journal of Photochemistry and Photobiology B: Biology, 123, 13-22. http://dx.doi.org /10.1016/j.jphotobiol.2013.02.015

Grose, J. H., \& Mamo, S. K. (2012). Electrophysiological measurement of binaural beats: Effects of primary tone frequency and observer age. Ear and Hearing, 32(2), 187194. http://dx.doi.org/10.1097/AUD.0b013e318230bbbd

Grove, R. (2011). Thomas Budzynski. Journal of Neurotherapy, 15(2), 182-186, http://dx.doi.org/10.1080 /10874208.2011.570687

Gupta, S., Stankus, A., Fukuda, T., \& Okumura, Y. (2015). Caregiver Burden of Alzheimer's disease in Japan. Kantar Health. Retrieved from http://www.kantarhealth.com/docs /white-papers/caregiver-burden-of-alzheimer's-disease-injapan.pdf?sfvrsn $=6$

Hammond, D. C. (2005). Temporal Lobes and Their Importance in Neurofeedback. Journal of Neurotherapy, 9(1), 67-88. http://dx.doi.org/10.1300/J184v09n01_08

Hansen, N. (2014). Brain stimulation for combating Alzheimer's disease. Frontiers in Neurology, 5, 80. http://dx.doi.org /10.3389/fneur.2014.00080

Hardy, J. (2009), The amyloid hypothesis for Alzheimer's disease: A critical reappraisal. Journal of Neurochemistry, 110(4), 1129-1134. http://doi.org/10.1111/j.1471-4159.2009.06181.x

Hardy, J., \& De Strooper, B. (2017). Alzheimer's disease: Where next for anti-amyloid therapies? Brain, 140(4), 853-855. http://dx.doi.org/10.1093/brain/awx059

Hardy, J., \& Selkoe, D. J. (2002). The amyloid hypothesis of Alzheimer's disease: progress and problems on the road to therapeutics. Science, 297(5580), 353-356. http://dx.doi.org /10.1126/science.1072994

Heneka, M. T., Carson, M. J., Khoury, J. E., Landreth, G. E., Brosseron, F., Feinstein, D. L., ... Koistinaho, J. (2015). Neuroinflammation in Alzheimer's disease. The Lancet Neurology, 14(4), 388-405. http://dx.doi.org/10.1016/S14744422(15)70016-5 Retrieved from http://escholarship.org/uc /item/99h2f9m1

Herrmann, C. S. (2001). Human EEG responses to $1-100 \mathrm{~Hz}$ flicker: Resonance phenomena in visual cortex and their potential correlation to cognitive phenomena. Experimental Brain Research, 137(3-4), 346-353. http://dx.doi.org /10.1007/s002210100682

Hsiao, F.-J., Wang, Y.-J., Yan, S.-H., Chen, W.-T., \& Lin, Y.-Y. (2013). Altered Oscillation and Synchronization of DefaultMode Network Activity in Mild Alzheimer's Disease Compared to Mild Cognitive Impairment: An Electrophysiological Study. PLoS ONE,8(7), e68792. http://dx.doi.org/10.1371 /journal.pone.0068792

laccarino, H. F., Singer, A. C., Martorell, A. J., Rudenko, A., Gao, F., Gillingham, T. Z., ... Tsai, L.-H. (2016). Nature, 540, 230235. http://dx.doi.org/10.1038/nature20587

Jack, C. R., Knopman, D. S., Jagust, W. J., Petersen, R. C., Weiner, M. W., Aisen, P. S., ... Trojanowski, J. Q. (2013). Tracking pathophysiological processes in Alzheimer's disease: An updated hypothetical model of dynamic biomarkers. The Lancet Neurology, 12(2), 207-216. http://dx.doi.org/10.1016/S1474-4422(12)70291-0

Jeong, J. (2004). EEG dynamics in patients with Alzheimer's disease. Clinical Neurophysiology, 115(7), 14901505. http://dx.doi.org/10.1016/j.clinph.2004.01.001

Kashefpoor, M., Rabbani, H., \& Barekatain, M. (2016). Automatic diagnosis of mild cognitive impairment using electroencephalogram spectral features. Journal of Medical Signals and Sensors, 6(1), 25-32. Retrieved from https://www.ncbi.nlm.nih.gov/pmc/articles/PMC4786960/

Keizer, A. W. (2010). The effect of gamma enhancing neurofeedback on the control of feature bindings and intelligence measures. International Journal of Psychophysiology, 75(1), 25-32. http://dx.doi.org/10.1016 /j.ijpsycho.2009.10.011

Kikuchi, M., Wada, Y., Takeda, T., Oe, H., Hashimoto, T., \& Koshino, Y. (2002). EEG harmonic responses to photic stimulation in normal aging and Alzheimer's disease: differences in interhemispheric coherence. Clinical Neurophysiology, 113(7), 1045-1051. http://dx.doi.org /10.1016/S1388-2457(02)00129-3

Kitagawa, N., \& Sakurai, M. (2016). Memantine-induced sustained unconsciousness. Neurology and Clinical Neuroscience, 4(6), 236-238. http://dx.doi.org/10.1111 /ncn3.12076

Kropotov, J. D. (2010). Alzheimer's Disease. In Quantitative EEG, event-related potentials and neurotherapy (pp. 463-468). San Diego, CA: Academic Press Inc.

Kuskowski, M. A., Mortimer, J. A., Morley, G. K., Malone, S. M., \& Okaya, A. J. (1993). Rate of cognitive decline in Alzheimer's disease is associated with EEG alpha power. Biological psychiatry, 33(8-9), 659-662. http://dx.doi.org/10.1016/00063223(93)90108-P

Leinenga, G., \& Götz, J. (2015). Scanning ultrasound removes amyloid- $\beta$ and restores memory in an Alzheimer's disease mouse model. Science Translational Medicine, 7(278), 278ra33. http:/dx.doi.org/10.1126/scitrans/med.aaa2512

Lichtenberg, P. A., Murman, D. L., \& Mellow, A. M. (2003). Handbook of dementia: Psychological, neurological, and psychiatric perspectives. Hoboken, NJ: John Wiley \& Sons.

Lladó, A., Antón-Aguirre, S., Villar, A., Rami, L., \& Molinuevo, J. L. (2008). Impacto psicológico del diagnóstico de la enfermedad de Alzheimer [Psychological impact of the diagnosis of 
Alzheimer's disease]. Neurología, 23(5), 294-298. Abstract in English: http://cat.inist.fr/?aModele $=$ afficheN\&cpsidt $=20532670$

Lucas Koberda, J. (2014). Z-score LORETA neurofeedback as a potential therapy in cognitive dysfunction and dementia. Journal of Psychology \& Clinical Psychiatry, 1(6), 00037. http://dx.doi.org/10.15406/jpcpy.2014.01.00037

Luijmes, R. E., Pouwels, S., \& Boonman, J. (2016). The effectiveness of neurofeedback on cognitive functioning in patients with Alzheimer's disease: Preliminary results. Neurophysiologie Clinique/Clinical Neurophysiology, 46(3), 179-187. http://dx.doi.org/10.1016/j.neucli.2016.05.069

Matsunaga, S., Kishi, T., \& Iwata, N. (2015). Memantine monotherapy for Alzheimer's disease: A systematic review and meta-analysis. PloS ONE, 10(4), e0123289. http://dx.doi.org/10.1371/journal.pone.0123289

Mewborn, C., Renzi, L. M., Hammond, B. R., \& Miller, L. S. (2015). Critical Flicker Fusion Predicts Executive Function in Younger and Older Adults. Archives of Clinical Neuropsychology, 30(7), 605-610. http://dx.doi.org/10.1093 /arclin/acv054

Moretti, D. V. (2015). Conversion of mild cognitive impairment patients in Alzheimer's disease: prognostic value of Alpha3/Alpha2 electroencephalographic rhythms power ratio. Alzheimer's Research \& Therapy, 7, 80. http://dx.doi.org /10.1186/s13195-015-0162-x

Moretti, D. V., Babiloni, C., Binetti, G., Cassetta, E., Dal Forno, G., Ferreric, F., ... Rossini, P. M. (2004). Individual analysis of EEG frequency and band power in mild Alzheimer's disease. Clinical Neurophysiology, 115(2), 299308. http://dx.doi.org/10.1016/S1388-2457(03)00345-6

Moretti, D. V., Prestia, A., Binetti, G., Zanetti, O., \& Frisoni, G. B. (2013). Increase of theta frequency is associated with reduction in regional cerebral blood flow only in subjects with mild cognitive impairment with higher upper alpha/low alpha EEG frequency power ratio. Frontiers in Behavioral Neuroscience, $\quad 7, \quad 188 . \quad$ http://dx.doi.org/10.3389 /fnbeh.2013.00188

Moretti, D. V., Prestia, A., Fracassi, C., Binetti, G., Zanetti, O., \& Frisoni, G. B. (2012). Specific EEG changes associated with atrophy of hippocampus in subjects with mild cognitive impairment and Alzheimer's disease. International Journal of Alzheimer's Disease, 2012, 253153. http://dx.doi.org/10.1155 /2012/253153

Olazarán, J., Reisberg, B., Clare, L., Cruz, I., Peña-Casanova, J., del Ser, T., ... Muñiz, R. (2010). Eficacia de las terapias no farmacológicas en la enfermedad de Alzheimer: una revisión sistemática [Nonpharmacological therapies in Alzheimer's disease: A systematic review of efficacy]. Dementia and Geriatric Cognitive Disorders, 30(2), 161-178. http://dx.doi.org/10.1159/000316119

Olmstead, R. (2005) Use of Auditory and Visual Stimulation to Improve Cognitive Abilities in Learning-Disabled Children. Journal of Neurotherapy, 9(2), 49-61, http://dx.doi.org/10.1300/J184v09n02_04

Orrell, M., Yates, L., Leung, P., Kang, S., Hoare, Z., Whitaker, C., ... Orgeta, V. (2017). The impact of individual Cognitive Stimulation Therapy (iCST) on cognition, quality of life, caregiver health, and family relationships in dementia: A randomised controlled trial. PLoS Medicine, 14(3), e1002269. http://dx.doi.org/10.1371/journal.pmed.1002269

Pastor, M. A., Artieda, J., Arbizu, J., Valencia, M., \& Masdeu, J. C. (2003). Human cerebral activation during steady-state visual-evoked responses. Journal of Neuroscience, 23(37), 11621-11627. http://www.jneurosci.org/content/23/37 111621.full

Peinado Portero, A. I. (1998). Burnout en cuidadores principales de pacientes con Alzheimer: El síndrome del asistente desasistido [Burnout in primary caregivers of patients with Alzheimer's: The unassisted assistant síndrome]. Anales de
Psicología, 14(1), 83-93. http://search.proquest.com /openview/e620580521a6d9b1b0331c6467e2e422/1?pqorigsite $=$ gscholar $\& \mathrm{cbl}=1606360$

Poil, S.-S., de Haan, W., van der Flier, W. M., Mansvelder, H. D., Scheltens, P., \& Linkenkaer-Hansen, K. (2013). Integrative EEG biomarkers predict progression to Alzheimer's disease at the $\mathrm{MCl}$ stage. Frontiers in Aging Neuroscience, 5, 58. http://dx.doi.org/10.3389/fnagi.2013.00058

Politoff, A. L., Monson, N., Hass, P., \& Stadler, R. (1992). Decreased alpha bandwidth responsiveness to photic driving in Alzheimer disease. Electroencephalography and Clinical Neurophysiology, 82(1), 45-52. http://dx.doi.org/10.1016 /0013-4694(92)90181-G

Prieto Jurczynska, C., Eimil Ortiz, M., López de Silanes de Miguel, C., \& Llanero Luque, M. (2011). Impacto social de la enfermedad de Alzheimer y otras demencias 2011. Retrieved from Fundación Española de Enfermedades Neurologicas, La Fundacion del Cerebro website: http://www.fundaciondelcerebro.es/docs/imp_social_alzheime r.pdf

Pritchard, W. S., Duke, D. W., \& Coburn, K. L. (1991). Altered EEG dynamical responsivity associated with normal aging and probable Alzheimer's disease. Dementia and Geriatric Cognitive Disorders, 2(2), 102-105. http://dx.doi.org/10.1159 1000107183

Rana, M., Varan, A. Q., Davoudi, A., Cohen, R. A., Sitaram, R., \& Ebner, N. C. (2016). Real-Time fMRI in Neuroscience Research and Its Use in Studying the Aging Brain. Frontiers in Aging Neuroscience, 8, 239. http://dx.doi.org/10.3389 /fnagi.2016.00239

Rodrigues, C., Castro, F. V., \& Spanish Red Cross. (2014). Personality changes in Alzheimer's disease. Revista INFAD de Psicología, 5(1), 177-186. http://dx.doi.org/10.17060 /ijodaep.2014.n1.v5.660

Rodriguez, G., Arnaldi, D., \& Picco, A. (2011). Brain Functional Network in Alzheimer's Disease: Diagnostic Markers for Diagnosis and Monitoring. International Journal of Alzheimer's Disease, 2011, 481903. http://dx.doi.org /10.4061/2011/481903

Rodriguez, G., Copello, F., Vitali, P., Perego, G., \& Nobili, F. (1999). EEG spectral profile to stage Alzheimer's disease. Clinical Neurophysiology, 110(10), 1831-1837. http://dx.doi.org/10.1016/S1388-2457(99)00123-6

Ross, B., Miyazaki, T., Thompson, J., Jamali, S., \& Fujioka, T. (2014). Human cortical responses to slow and fast binaural beats reveal multiple mechanisms of binaural hearing. Journal of Neurophysiology, 112(8), 1871-1884. http://dx.doi.org/10.1152/jn.00224.2014

Ross, B., Picton, T. W., Herdman, A. T., \& Pantev, C. (2004). The effect of attention on the auditory steady-state response. Neurology \& Clinical Neurophysiology, 2004, 2225. https://www.ncbi.nlm.nih.gov/pubmed/16012602

Rusinek, H., Endo, Y., De Santi, S., Frid, D., Tsui, W.-H., Segal, S., ... de Leon, M. J. (2004). Atrophy rate in medial temporal lobe during progression of Alzheimer disease. Neurology, 63(12), 2354-2359. http://dx.doi.org/10. 1212/01.WNL.0000148602.30175.AC

Sadaghiani, S., \& Kleinschmidt, A. (2016). Brain Networks and $\alpha-$ Oscillations: Structural and Functional Foundations of Cognitive Control. Trends in Cognitive Sciences, 20(11), 805817. http://dx.doi.org/10.1016/j.tics.2016.09.004

Schneider, L. S., Dagerman, K. S., Higgins, J. P. T., \& McShane, R. (2011). Lack of Evidence for the Efficacy of Memantine in Mild Alzheimer Disease. Archives of Neurology, 68(8), 991998. http://dx.doi.org/10.1001/archneurol.2011.69

Siever, D. (2007). Audio-Visual Entrainment. In Handbook of neurofeedback: Dynamics and clinical applications (pp. 155183. Boca Raton, FL: CRC Press. http://dx.doi.org/10.1201 /b14658-11 
Skjerve, A., Holsten, F., Aarsland, D., Bjorvatn, B., Nygaard, H. A., \& Johansen, I. M. (2004). Improvement in behavioral symptoms and advance of activity acrophase after short-term bright light treatment in severe dementia. Psychiatry and Clinical Neurosciences, 58(4), 343-347. http://dx.doi.org /10.1111/j.1440-1819.2004.01265.x

Snowdon, D. A., Greiner, L. H., Mortimer, J. A., Riley, K. P., Greiner, P. A., \& Markesbery, W. R. (1997). Brain infarction and the clinical expression of Alzheimer disease: The Nun Study. Journal of the American Medical Association, 277(10), 813-817. /jama.1997.03540340047031

http://dx.doi.org/10.1001

Sommer, A. P. (2015). A mechanism for ultrasound/light-induced biostimulation. Annals of Translational Medicine, 3(19), 291. http://dx.doi.org/10.3978/j.issn.2305-5839.2015.09.18

Staufenbiel, S. M., Brouwer, A.-M., Keizer, A. W., \& van Wouwe, N. C. (2014). Effect of beta and gamma neurofeedback on memory and intelligence in the elderly. Biological Psychology, 95, 74-85. http://dx.doi.org/10.1016/j.biopsycho.2013.05.020

Suárez-Calvet M, Caballero, M. A. A., Kleinberger, G., Bateman, R. J., Fagan, A. M., Morris, J. C., ... Haass, C. (2016). Dominantly Inherited Alzheimer Network. Early changes in CSF sTREM2 in dominantly inherited Alzheimer's disease occur after amyloid deposition and neuronal injury. Science Translational Medicine, 8(369), 369ra178. http://dx.doi.org /10.1126/scitranslmed.aag1767

Surmeli, T., Eralp, E., Mustafazade, I., Kos, H., Özer, G. E., \& Surmeli, O. H. (2016). Quantitative EEG Neurometric Analysis-Guided Neurofeedback Treatment in Dementia. 20 Cases. How Neurometric Analysis Is Important for the Treatment of Dementia and as a Biomarker? Clinical EEG and Neuroscience, 47(2), 118-133. http://dx.doi.org/10.1177 $/ 1550059415590750$

Tallon-Baudry, C., \& Bertrand, O. (1999). Oscillatory gamma activity in humans and its role in object representation. Trends in Cognitive Sciences, 3(4), 151-162. http://dx.doi.org/10.1016/S1364-6613(99)01299-1

Tallon-Baudry, C., Bertrand, O., Wienbruch, C., Ross, B., \& Pantev, C. (1997). Combined EEG and MEG recordings of visual $40 \mathrm{~Hz}$ responses to illusory triangles in human. Neuroreport, 8(5), 1103-1107. http://dx.doi.org/10.1097 /00001756-199703240-00008

Teplan, M., Krakovská, A., \& Štolc, S. (2006a). Short-term effects of audio-visual stimulation on EEG. Measurement Science Review, 6(2), 67-70. Retrieved from http://citeseerx.ist.psu.edu/viewdoc/summary?doi=10.1.1.214. 4114
Teplan, M., Krakovská, A., \& Štolc, S. (2006b). EEG responses to long-term audio-visual stimulation. International journal of psychophysiology, 59(2), 81-90. http://dx.doi.org/10.1016 /j.ijpsycho.2005.02.005

Tsolaki, A., Kazis, D., Kompatsiaris, I., Kosmidou, V., \& Tsolaki, M. (2014). Electroencephalogram and Alzheimer's Disease: Clinical and Research Approaches. International Journal of Alzheimer's Disease, 2014, 349249. http://dx.doi.org/10.1155 /2014/349249

Van der Hiele, K., Vein, A. A., Kramer, C. G., Reijntjes, R. H., van Buchem, M. A., Westendorp, R. G., ... Middelkoop, H. A. (2007). Memory activation enhances EEG abnormality in mild cognitive impairment. Neurobiology of Aging, 28(1), 85-90. http://dx.doi.org/10.1016/j.neurobiolaging.2005.11.006

Van Deursen, J. A., Vuurman, E. F. P. M., Verhey, F. R. J., van Kranen-Mastenbroek, V. H. J. M., \& Riedel, W. J. (2008). Increased EEG gamma band activity in Alzheimer's disease and mild cognitive impairment. Journal of Neural Transmission, 115(9), 1301-1311. http://dx.doi.org/10.1007 /s00702-008-0083-y

Verret, L., Mann, E. O., Hang, G. B., Barth, A. M. I., Cobos, I., Ho, K., ... Palop, J. J. (2012). Inhibitory interneuron deficit links altered network activity and cognitive dysfunction in Alzheimer model. Cell, 149(3), 708-721. http://dx.doi.org /10.1016/j.cell.2012.02.046

Williams, J., Ramaswamy, D., \& Oulhaj, A. (2006). $10 \mathrm{~Hz}$ flicker improves recognition memory in older people. BMC Neuroscience, 7, 21. http://dx.doi.org/10.1186 /1471-2202-721

Zambrano Cruz, R., \& Ceballos Cardona, P. (2007). Síndrome de carga del cuidador [Caregiver burden síndrome]. Revista Colombiana de Psiquiatría, 36(Suppl. 1), 26-39. Retrieved from http://www.scielo.org.co /scielo.php?script=sci_arttext\&pid=S0034$74502007000500005 \&$ \&ng $=$ en\&tlng $=e s$

Zoefel, B., Huster, R. J., \& Herrmann, C. S. (2011). Neurofeedback training of the upper alpha frequency band in EEG improves cognitive performance. Neurolmage, 54(2), $1427-1431$. /j.neuroimage.2010.08.078 http://dx.doi.org/10.1016

Received: June 1, 2017

Accepted: June 21, 2017

Published: June 30, 2017 